\title{
Awareness challenges of mental health disorder and dementia facing stigmatisation and discrimination: a systematic literature review from Sub-Sahara Africa
}

\author{
Susanne Spittel ${ }^{1,2}$, André \\ Maier $^{1}$, Elke Kraus ${ }^{3}$ \\ ${ }^{1}$ Charité - Universitätsmedizin \\ Berlin, corporate member \\ of Freie Universität Berlin, \\ Humboldt-Universität zu Berlin, \\ and Berlin Institute of Health, \\ Department of Neurology, Berlin, \\ Germany \\ ${ }^{2}$ University of Bremen, Health \\ Science Bremen - Institute \\ for Public Health and Nursing \\ Research (IPP), Bremen, \\ Germany \\ ${ }^{3}$ Alice Salomon University of \\ Applied Sciences Berlin, Berlin, \\ Germany
}

Background Mental health disorders (MHD) are leading causes of disabilities. Awareness of MHD in Sub-Saharan Africa (SSA) is crucial to both health care professionals and general community if those affected by MHD are to be allowed to live in dignity and be socially included, rather than being treated as outcasts or witches, as is presently the case. Therefore, this review aims to map and summarise the extent to which awareness of MHD and dementia in SSA challenges stigmatisation issues.

Methods A systematic review was conducted using electronic databases (PubMed, CINAHL, PsycINFO). A content analysis of selected studies was performed. Findings on awareness challenges and stigmatisation were identified and categorised.

Results A total of 230 publications were screened, 25 were selected for this review. The results demonstrate strong supernatural beliefs influencing peoples' perceptions of diseases. These perceptions promote stigmatising attitudes towards people with MHD and dementia. The education level correlated with stigmatising attitudes, whereby higher educated people were less likely to distance themselves socially from people with MHD and from people living with dementia (PwD). Astonishingly, even people educated in health issues (eg, nurses, medical practitioners) tended to have strong beliefs in supernatural causations of diseases, like witchcraft, and hold negative attitudes towards MHD and PwD.

Conclusions This review provides some evidence on the influence of traditional beliefs on MHDs in SSA. Those beliefs are powerful and exist in all segments in SSA-communities, promoting superstitious perceptions on diseases and stigmatisation. Awareness and education campaigns on MHD are absolutely mandatory to reduce stigmatisation.

\section{Correspondence to:}

Susanne Spittel, M.Sc

Lychener Strasse 52

10437 Berlin

Germany

s.spittel@gmail.com
Mental health disorders (MHD) are among the leading causes of disability and are more prevalent among the younger population (0-59 years), whereas chronic diseases such as dementias are more prevalent in older populations (60+ years) [1]. About 1 in 10 persons live with MHD (PwMHD), whilst the provision of mental health care is lacking [2]. According to the World Bank (2016), 84\% of the world's population lives in low and middle income countries (LAMIC), 14\% in Sub-Saharan African countries (SSA). In many LAMIC, particular in Africa, policies and legislation rarely exist to establish essential mental health services [3,4]. Data from Africa show highest scores in illiteracy and lowest scores in expenditure on mental health, mental health resources, 
and lowest disability-adjusted life years by neuropsychiatric conditions [3]. Besides, SSA counts a high prevalence of infectious diseases, which impacts the prevalence of probable common MHD (eg, HIV-related dementia) [5-8]. For instance, estimated HIV-related dementia incidence cases in studied populations with HIV/AIDS varies up to 36\% [9]. Moreover, the number of people living with dementia (PwD) is increasing - especially in LAMIC as numbers rise more prominently compared to the developed world $[10,11]$. By 2050 the number of PwD will more than triple in LAMIC [11], caused by infectious diseases like tuberculosis or HIV, but also by a growing middle class population of Africa with an improved sustainable livelihood that allows them to seek better health care, which in turn is likely to contribute to life expectancy, morbidity and mortality rates $[8,12]$. However, most of these conditions are insufficiently diagnosed and remain untreated [13,14]. Furthermore, PwMHD often experience stigmatisation; even their families, and friends as well as health care providers experience the impact of public stigma [15]. Perceiving stigma is strongly associated with MHD and occurs more frequently in developing countries [16]. Worldwide, people from various cultures hold different traditional beliefs, which can be powerful in healing people on the one hand, but on the other hand, strong beliefs can also affect attitudes towards PwMHD, even amongst people that have received medical education [17]. Supernatural attitudes to an illness exist especially in societies where traditions dominate society [18]. In most SSA-cultures, people strongly believe in supernatural powers [19,20]. As long as there is no awareness and "name" for diseases (eg, for dementia), people's behaviour - especially if people are seen as acting "strange" - can be misinterpreted and lead to accusation and exclusion [21].

\section{Objective}

This review aims to identify awareness and knowledge as well as attitudes (eg, beliefs, feelings, and behaviours) around MHD and dementia in SSA that reveal stigmatisation. Hypothetically, it is assumed that supernatural traditional beliefs challenge perceptions and concepts on MHD and dementia and result in stigmatisation of people living with such diseases in SSA. The review targets peoples' awareness and knowledge of MHD and dementia, their attitudes towards PwMHD and PwD, as well as the stigmatisation grounded in supernatural beliefs.

\section{METHODS}

\section{Data sources and search strategy}

A systematic literature review was conducted using online databases in accordance with the PRISMA statement [22]. Different search strategies were performed systematically to identify published studies reporting on awareness and knowledge around MHD and dementia in SSA that reveals stigmatisation. The following electronic databases were used: PubMed ${ }^{\circledR}$ including MEDLINE ${ }^{\circledR}, \mathrm{CINAHL}$ and PsycINFO ${ }^{\circledR}$. Key words included 'mental health', 'dementia' or 'Alzheimer*', and 'education' or 'awareness', and 'stigma*' or 'witch*', and 'Africa'. Within the databases, key words were searched in combination. Title and abstract of articles were screened for relevance based on inclusion criteria. Reference lists were hand checked to identify supplementary studies, and a "grey" literature search was conducted. Additionally, articles, books, chapters, reports, non-empirical studies, and commentaries were used for a more in-depth understanding.

\section{Study selection}

For review inclusion, studies based on following criteria were selected. Studies were required to (a) focus on MHD or dementia, especially focussing on diseases which can cause abnormal "strange" behaviour in the affected persons; (b) address awareness or education, and (c) report on stigmatisation on those diseases. Because of differences on cultural values and beliefs between Northern Africa (Arabic culture) and SSA (Gupta, Hanges \& Dorfman, 2002), articles were required (d) to relate to SSA. Studies published in English or German (e) were included. There was no time limitation for inclusion.

\section{Outcomes of interest}

Primary outcome of interest was an influencing factor on the awareness and concepts on MHD and dementia. Traditional beliefs in Sub-Sahara Africa such as witchcraft were considered as influencing factors. Additionally, stigmatisation issues concerning MHD and dementia and its grounding in supernatural beliefs were of interest. 


\section{Data extraction and quality assessment}

In a first step data were extracted by country where results were conducted, method of the study, participants and sample size, and the objective of the study. In a second step data were extracted reporting on concepts on MHD and dementia, attitudes towards, and stigmatisation of people living with MHD and dementia. Extracted data were classified separately for health care professionals (HCP; eg, nurses, caregivers, medical practitioners, care-providers), and general community members (GCM; eg, community members, children, and clergy). Full texts of selected studies were checked for representation of sampling, quality of methods applied, and reporting strategy.

\section{RESULTS}

\section{Systematic review}

In total 230 potentially relevant publications were identified via systematic search in the electronic databases: PubMed (182 references), PsycINFO (8 references), CINAHL (40 references). After removing duplications, papers were screened based on title and abstract. 55 relevant publications were selected for further examination. In the final selection, 25 articles met all relevant inclusion criteria and were involved (Figure 1).

\section{Study characteristics}

Most studies focussed on awareness challenges on MHD in general $(n=21)$, four studies investigated dementia. Reviewed studies originated from Nigeria $(\mathrm{n}=10)$, Ghana $(\mathrm{n}=2)$, Republic of Congo $(\mathrm{n}=1)$, Uganda $(\mathrm{n}=2)$, Ethiopia $(\mathrm{n}=2)$, Tanzania $(\mathrm{n}=1)$, Zambia $(\mathrm{n}=1)$, Zimbabwe $(\mathrm{n}=1)$, South Sudan $(\mathrm{n}=1)$, and South Africa $(\mathrm{n}=4)$.

Methodologies included studies applying a quantitative approach by retrieving questionnaires $(\mathrm{n}=13)$ or a qualitative design by conducting interviews or focus group discussions $(n=10)$. Two studies combined quantitative and qualitative methods. Main results were categorised according to the following themes: (I) concepts, and knowledge on MHD and dementia, (II) perceptions on witchcraft, (III) attitudes to-

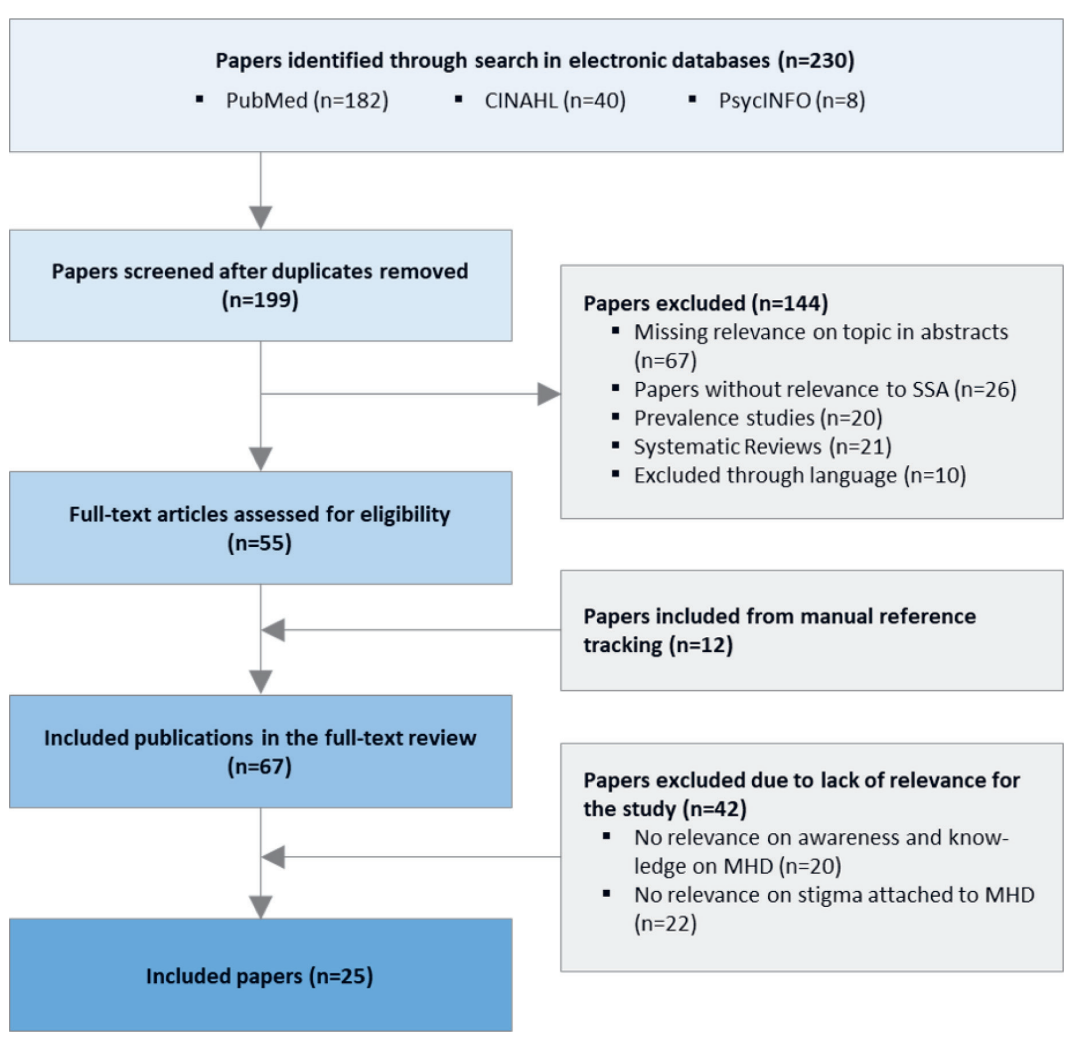

Figure 1. Flow-chart of search strategy used to identify the studies relevant for the review. MHD - mental health disorders, SSA - Sub-Saharan Africa. wards PwMHD and PwD, and (VI) stigmatisation of PwMHD and PwD. Characteristics of the reviewed studies are summarised in Table 1.

\section{Concepts and knowledge on MHD and dementia}

The review reveals that people in SSA hold different explanations on the causation of MHD and dementia. Explanations derive from biological, psychological, and spiritual concepts, or other explanations, classified and summarised in Table 2.

Biological explanations are used least often to describe MHD's or dementia's causation. In terms of MHD, HCP are more likely to use biological explanations compared to GCM $[19,24]$. Also, PwD themselves or their relatives and caregivers, mostly tended to lack knowledge of dementia [31,40].

Psychosocial explanations are considered to be more prominent causes. Especially misuse of drugs and alcohol are most frequently seen to cause MHD (up to $80 \%$ ); followed by stress (up to $81 \%$ ) or the burden of poverty $(53 \%)[24,32,34]$. 


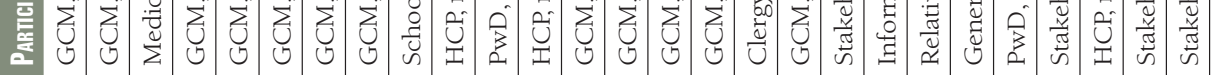

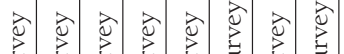

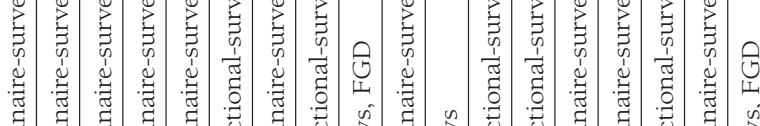

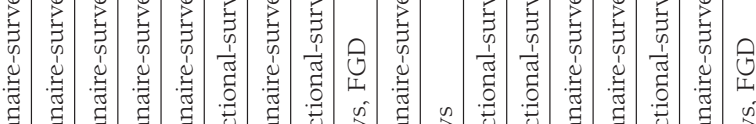

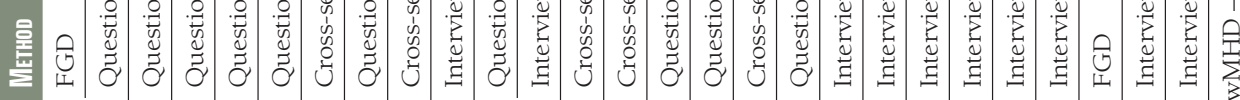

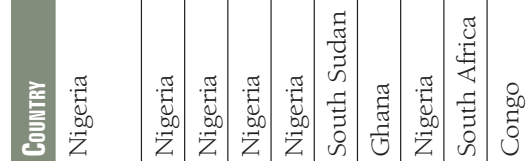

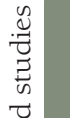

$\frac{\widetilde{Z}}{3}$

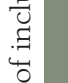

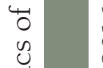

:

苞

苛

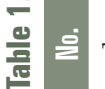

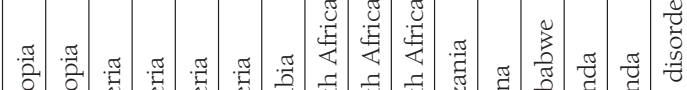

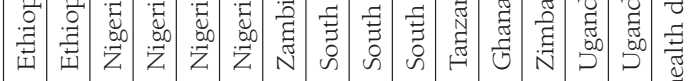

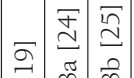

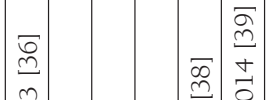

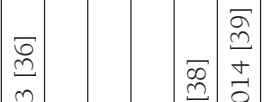

च

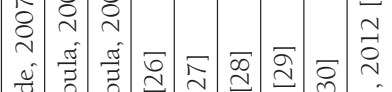

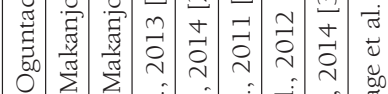

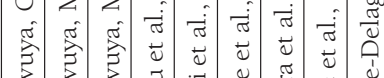

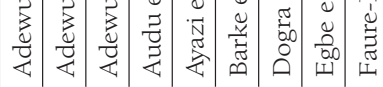

인 $\infty$

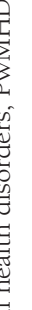


Table 2. Classification of concepts on MHD and dementia

\begin{tabular}{|c|c|c|c|c|}
\hline Category & CONCEPT ON MHD & GCM in \% & HCP IN \% & Representative studies \\
\hline \multirow[t]{3}{*}{ Biological explanations } & Brain illness* & R: $0.9-38.0 *$ & $81.8 *$ & {$[26,31,34]$} \\
\hline & Brain infection & R: $25.0-30.4 \dagger$ & 49.4 & {$[19,31]$} \\
\hline & Heredity & R: 10.3-38.3 & 32.7 & {$[19,24,25,29,34]$} \\
\hline \multirow[t]{3}{*}{ Psychosocial factors } & Stress* & R: $6.7-80.8 \dagger$ & $58.3 \dagger$ & {$[6,19,24,29,31,32,34,37,39,40,42,43]$} \\
\hline & Personal failure & R: $10.2-61.2$ & $20.2 \dagger$ & {$[19,24,28,29,36]$} \\
\hline & Drug, alcohol misuse & R: $9.5-80.8 \dagger$ & $67.9 \dagger$ & {$[6,19,24,26,32,33,37,42]$} \\
\hline \multirow[t]{2}{*}{ Supernatural explanations } & Witchcraft, evil spirit* & R: $19.9-65.5^{\dagger}$ & $53.8 \dagger$ & {$[6,19,20,24-27,29-34,37-43]$} \\
\hline & Punishment by God* & R: 9.3-50.1† & $6.4 \dagger$ & {$[6,19,24-26,31,32,34,37,40,43]$} \\
\hline \multirow[t]{4}{*}{ Other explanations } & Madness* & + & $+\dagger$ & {$[6,23,41-44]$} \\
\hline & Normal part of ageing* & R: $18.2-71.9 \dagger$ & $\dagger$ & {$[23,31,40]$} \\
\hline & Contagious disease* & $13.2 *$ & $\dagger$ & {$[6,31,43]$} \\
\hline & "Whites peoples disease"* & $\mathrm{n} / \mathrm{a}$ & $\dagger$ & [38] \\
\hline
\end{tabular}

MHD - mental health disorders, GCM - general community members, HCP - health care professionals (eg, medical practitioners, nurses, caregivers), $\mathrm{R}$ - Range, $\mathrm{n} / \mathrm{a}$ - not applicable

*Addressed by dementia studies.

$\dagger$ Qualitative results involved.

Furthermore, misconceptions exist very frequently in the way that MHD or dementia are not perceived as diseases but as madness, a source of witchcraft or sorcery (up to 66\%). Those supernatural explanations are predominantly considered to cause MHD and dementia occurring in all segments of communities, including PwMHD itself and HCPs [34]. Especially people lacking knowledge of the disease aetiology, witchcraft was identified as the cause $[20,41]$. The behaviour of $\mathrm{PwD}$ is perceived as strange, abnormal, and dangerous which makes people think about witchcraft $[30,38]$. For instance, Zambian interviewees acknowledged: "This is a mad person [...]"; "People still think that mental illness is caused by evil spirits. [...];" or that PwMHD are bewitched [6]. In Ghana, it is common that people tend to understand MHD as the "work of witches': "People don't really understand the causes, so they attribute it to witches [...]."; "People see madness, epilepsy and witchcraft as all the same. They see mental illness as the doing of witches and their curses" [41]. Likewise, informal caregivers from South Africa, who do not understand the illness of their relatives, believed their disease was caused by the environment or witchcraft [20]. Moreover, high numbers of medical doctors (in Nigeria over 50\%) saw spiritual explanations as the aetiology of MHD [19].

\section{Belief in witchcraft}

Spiritual beliefs, like 'witchcraft', 'Satanism', 'evil spirits' or 'punishment from God' were found to be very strong and leading to misunderstanding the aetiology of MHD or dementia in the following countries: Nigeria [19,24,26,29,34,37], Ghana [41], South Africa [20,30], Uganda [43], Tanzania [40], Zambia [6], Zimbabwe [42], South Sudan [27], and Ethiopia [32]. Those spiritual beliefs, seen as causing diseases, are also associated with negative attitudes towards PwMHD and higher stigmatisation. They can prevent people from seeking professional help, can impact concepts of caregiving, and lead to marginalisation of PwMHD $[20,25,27,30,34,43]$.

\section{Attitudes towards PwMHD and PwD}

Negative attitudes and stigmatisation against PwMHD are found to be widespread in these countries: Nigeria [23], Ghana [28,41], Republic of Congo [31], Tanzania [40], South Sudan [27], Uganda [43,44], Ethiopia [33], Zambia [6], Zimbabwe [42], and South Africa [38]. Negative attitudes are held by different groups in society - most evident among GCM, but also within families, among HCP and health care users, as well as within the government level or among policy makers $[6,23,24,26-28,30,33,35,37,41,43]$. Also, even if people were friends with PwMHD, they hold negative attitudes towards them, which was found in South Africa and Zambia [6,30]. The finding that negative attitude towards PwMHD are not limited to adults was established in a Nigerian schoolchildren survey [29].

Generally, PwMHD or PwD are perceived to be dangerous or aggressive, to be a burden to society as well as a public nuisance. Among both GCM and HCP, perceived dangerousness or aggressiveness are two of the main prejudiced perceptions held towards PwMHD, as the majority of reviewed studies indicate (Table 3).

Such negative perceptions can arise from fear, focusing on the hardship of caregiving or lacking interest, motivation, and knowledge around MHD [19,20,44]. A South African study disclosed that GCM and 
Table 3. Attitudes and prejudices towards PwMHD and PwD

\begin{tabular}{|c|c|c|c|}
\hline AtTITUDES AND PREJUDICES* & GCM in \% & HCP IN \% & REPRESENTATIVE STUDIES \\
\hline Are dangerous & R: 57.9-96.7‡ & $70.5 \ddagger$ & {$[6,19,25,27,34,36,43,45]$} \\
\hline Show a violent/aggressive behaviour & R: $21.8-96.7 \ddagger$ & R: 51.0-53.8末 & {$[6,19,20,26,27,29,30,32,34,35,37,42]$} \\
\hline Are frightening or scary $\dagger$ & R: 23.3-86.4‡ & R: 26.9-37.5市 & {$[6,19,20,26,27,30,32,34-38]$} \\
\hline Making others ashamed $\dagger$ & R: $11.3-86.1 \neq$ & $26.9 \neq$ & {$[19,23,25,27,29,33-35,39,43]$} \\
\hline Are a burden to individuals, families, and communities $\dagger$ & R: 37.3-56.3‡ & 韦 & {$[20,28,31,36,40,43]$} \\
\hline Are different; behave strange $\dagger$ & R: 33.4-79.7‡ & \# & {$[28,31,32,36,38]$} \\
\hline Are a public nuisance & R: $15.0-97.8$ & $\mathrm{n} / \mathrm{a}$ & {$[26,34,35]$} \\
\hline Are unpredictable or lacking self-control & 57.9 & R: $59.0-85.9$ & {$[19,29]$} \\
\hline
\end{tabular}

PwMHD - people living with mental health disorders, PwD - people living with dementia, GCM - general community members, HCP - health care professionals (eg, medical practitioners, nurses, caregivers), $\mathrm{R}$ - range, $\mathrm{n} / \mathrm{a}$ - not applicable

*Attitudes are listed in order of the relevance mentioned in the papers reviewed.

$\uparrow$ Addressed by dementia studies.

¥Results from qualitative studies involved.

family members are afraid of the PwD and that even nurses hold such attitudes until they started working with them [38]. This not only leads to misinterpretation of behaviours shown by PwMHD or PwD but also often relates to higher levels of stigmatising attitudes $[6,25,27,37,43]$.

Stigmatising attitudes can also concern the family of or people caring for PwMHD, professional health care providers, or whole mental health institutions $[6,20,25,30,36,44]$. The education level correlates with stigmatising attitudes, whilst people with higher education tend to keep less social distance towards PwMHD, or their relatives $[26,28,33]$. People with less knowledge show higher social distance $[6,20,27,29,35,36,39,44,46]$. Those attitudes and perceptions, especially being afraid of having conversations with PwMHD or believing that the presence of PwMHD might pose a risk to unaffected people, is observed to strengthen social isolation $[25,28,29]$.

\section{Stigmatisation of PwMHD and PwD}

In particular, social distance and exclusion of the PwMHD from the community (eg, keeping the ill person behind locked doors) is mainly addressed by the reviewed studies $[6,20,27,28,30,32,33,36,39-44]$. Both GCM and HCP would feel disturbed about sharing a room or their house with PwMHD or living next door to someone who is mentally ill, or even having PwMHD living in residential neighbourhoods (Table 4). A Zimbabwean study revealed that PwD are locked away as long as family members are re-

Table 4. Perceived stigma of PwMHD and PwD

\begin{tabular}{|c|c|c|c|c|}
\hline Categony & Perceeved stigma & BCM $10 \%$ & HCP $\mathrm{w} \%$ & RePRESENTATIVE STUDIES \\
\hline \multirow[t]{6}{*}{ Social isolation/distance } & Avoid contact /the person & R: $23.3-86.4$ & $\mathrm{n} / \mathrm{a}$ & {$[19,25-29,34,36,37,45]$} \\
\hline & Unwillingness of maintaining a friendship & R: $51.4-83.1$ & $\mathrm{n} / \mathrm{a}$ & {$[25,27,29,33,34]$} \\
\hline & Not marry* & R: $18.6-96.6^{\dagger}$ & $80.8 \dagger$ & {$[6,19,23,25-28,33,34,36,43]$} \\
\hline & Not share room & R: 47-84.5 & 64.1 & {$[19,25-27,34,35]$} \\
\hline & Locked away / keep behind Locked doors* & R: $24.3-47.8 \dagger$ & $\dagger$ & {$[28,33,36,39,40,43]$} \\
\hline & Isolation from the community* & $\mathrm{R}: 24.3-42.1 \dagger$ & $\dagger$ & {$[6,20,28,30,31,36,38,39,41-43]$} \\
\hline \multirow[t]{3}{*}{ Physical torture } & Throwing stones* & $\dagger$ & $\mathrm{n} / \mathrm{a}$ & {$[6,38]$} \\
\hline & Chained or tied them up & $\dagger$ & $\mathrm{n} / \mathrm{a}$ & {$[30,43]$} \\
\hline & Maltreatment or beaten* & $\dagger$ & $\mathrm{n} / \mathrm{a}$ & {$[30,38,44]$} \\
\hline \multirow[t]{3}{*}{ Mental torture/burden } & Living neglected, rejected, or blamed* & $65.5 \dagger$ & $\dagger$ & {$[6,20,23,29,30,33,38,41-44]$} \\
\hline & Being laughed at, or bullied* & $\dagger$ & $\mathrm{n} / \mathrm{a}$ & {$[23]$} \\
\hline & Being shunned* & $\dagger$ & $\mathrm{n} / \mathrm{a}$ & [23] \\
\hline \multirow[t]{4}{*}{ Worsened health situation } & Ignored by health care staff & $\dagger$ & $\dagger$ & {$[6,20,30]$} \\
\hline & Traditional healers instead of medical care* & R: $18-34 \dagger$ & $\mathrm{n} / \mathrm{a}$ & {$[20,37-40,42]$} \\
\hline & Inadequate or delayed health & $\dagger$ & $\dagger$ & {$[6,30,36]$} \\
\hline & Mental health service out of residential areas & R: 39.8-69.1 & $\mathrm{n} / \mathrm{a}$ & {$[28,36]$} \\
\hline \multirow[t]{4}{*}{ Job/education burden } & Work with a PwMHD & R: $43.1-84.8 \dagger$ & $\mathrm{R}: 32.1-39.7 \dagger$ & {$[19,25,27,34,42,44]$} \\
\hline & Getting no or filthy jobs & $\dagger$ & $\dagger$ & {$[6,43]$} \\
\hline & Schooling or studying with a PwMHD & $70.2 \dagger$ & $\mathrm{n} / \mathrm{a}$ & {$[29,43]$} \\
\hline & Employers passing applications over & 77.2 & $\mathrm{n} / \mathrm{a}$ & [28] \\
\hline
\end{tabular}

PwMHD - people living with mental health disorders, PwD - people living with dementia, GCM - general community members, HCP - health care professionals (eg, medical practitioners, nurses, caregivers), $\mathrm{R}$ - range, $\mathrm{n} / \mathrm{a}$ - not applicable

*Addressed by dementia studies.

$\uparrow$ Qualitative results involved. 
luctant to disclose the status of their relatives [40]. Even within families, relatives exclude their ill family members, for example, as these have to eat separately or are forced to live on the street [43]. It is frequently found that PwMHD are unable to lead normal lives because of social isolation [30,42]. Zambian stakeholders disclosed that PwMHD live in misery and loneliness without hope while community members bully and throw stones at them [6]. A Ghanaian study describes that especially women experience widespread physical abuse as communities force persons suspected of using witchcraft to move to designated areas called 'witch-camps' where these women undergo 'cleansing' rituals to rid them of witchcraft. They may also be expelled by the community, or even chased away by people intending to kill them [41]. In addition, the reviewed studies reveal stigmatisation through maltreatment (eg, being beaten by family members, or tied to a tree), and the point to influences on the health situation of PwMHD (eg, obtain service in a delay or being ignored by health care providers), as well as that PwMHD usually experience job disadvantages (Table 4).

Moreover, the stigma can influence whole families, HCP, or whole mental-health care hospitals. Also, families or carers of PwMHD often feel lonely and experience social isolation. Because of their involvement in care, they are often blamed by community members, eg, cannot attend church sessions, funerals, or other important traditional functions $[20,33,42]$. Even a whole neighbourhood can be stigmatised if PwMHD live there [6]. On the other hand, caregivers have to cope with stress, burnout through physical aggression, and destructive behaviour from PwMHD or PwD [31,40]. Another major challenge in providing care are financial constraints, eg, having problems with maintaining employment $[20,42]$.

\section{Relationship between findings}

The findings suggest that generally attitudes of people with poor knowledge, towards PwMHD were predominantly negative [35]. In addition, it was found that people assigning psychological causes to the medical conditions yield more positive attitudes towards PwMHD [33,35]. In contrast, people holding spiritual views of diseases' causations show higher social distance towards PwMHD [25,27,30,34,43]. It can be postulated that such negative attitudes may reflect a lack of understanding of clinical subtleties of MHD [36]. For example, an Ethiopian study revealed that people with awareness of diseases' signs and symptoms have less stereotyped attitudes and prejudices towards PwMHD [33]. Fortunately, people who cared for PwMHD or PwD, or people with knowledge of diseases causation show less stigmatising attitudes as they started to understand the disease $[25,38]$. Interviewed caregivers of PwD from Tanzania stressed the need for improved knowledge of care and support for PwD because of carer burden [40].

\section{DISCUSSION}

This appears to be the first systematic review based on studies focusing on awareness challenges of MHD and dementia in SSA and the related stigmatisation issue. Based on the results of this review, there is evidence that supernatural beliefs influence awareness and knowledge on MHD and this results in the stigmatisation of people living with those conditions in SSA. The review furthermore highlights findings on people's attitudes towards PwMHD and PwD, their awareness and knowledge of those conditions, and the issue of stigmatisation, grounded in supernatural beliefs.

\section{Discussion of essential key findings}

The 25 studies reviewed clearly show that people in SSA generally hold strong negative attitudes towards PwD $[23,40,47]$ and PwMHD $[6,19,34]$. Negative attitudes are widespread in SSA as they occur in Western-Africa, Eastern-Africa, and Southern-Africa $[20,30,48]$. Those negative attitudes are held by GCM and also by HCP, and arise precisely because people hold misperceptions on MHD or dementia [38]. It became clear that supernatural beliefs (eg, witchcraft, sorcery, evil spirits) play an important role to explain behaviours of PwMHD or PwD living in SSA as they influence people's concepts on causation of diseases. Such supernatural beliefs are still widespread and strong in SSA, eg, in West- and East-African Countries as well as in countries in Central- and Southern Africa [6,19,33,40-42,49]. Based on these findings it can be concluded that people possessing those traditional beliefs appear to be influenced in their understanding of diseases, regardless of whether they live in SSA or in other parts of the world. On the positive side, higher level of education or experience with caring for people living with such conditions can be seen as indicators for biological models of causation, reducing supernatural explanations for such diseases $[20,27,38,41]$. Awareness of MHD and dementia could help to lessen stigmatisation and minimise exclusion of PwMHD, PwD, and those who care for them [50]. However, the review also shows that PwD themselves, their caregivers, and HCP relate dementia to curses or witchcraft $[20,38,40,42]$. Alarm- 
ingly, more than half of medical Nigerian practitioners see witchcraft as potentially causing MHD [19]. This high percentage underpins the strong influence of supernatural beliefs on causation of diseases. It could be found that those issues are also relevant for other diseases like epilepsy, what results from Eastern and Central African studies [49,51]. Likewise, future HCP like Ugandan medical students believed in supernatural causes (eg, witchcraft) of epilepsy [49].

As long as HCP misinterpret the aetiology of MHD because of supernatural beliefs, hardship remains for PwMHD or PwD and their families to develop awareness and knowledge on their conditions. To this effect, awareness campaigns and mental health literacy programs are urgently needed $[28,30,39,40]$. Community awareness campaigns as well medical curricula need to deal with the impact of cultural beliefs [19].

As seen in Figure 2, it can be summarised that without such investigations - particularly in countries where awareness and knowledge on diseases lacks - supernatural beliefs will strengthen misperceptions about MHD and dementia. As long as people hold misperceptions of the causes of diseases, people will be less likely to obtain knowledge about diseases, or even to find the underlying cause of PwMHD's or PwD's behaviours. Those beliefs, as well as a lack of awareness and knowledge is likely to promote negative attitudes and stigmatisation. If a person experiences stigmatisation, like physical abuse, exclusion and loneliness $[6,41]$, this can lead to anxiety, fear and stress for that person and can promote a higher risk for dementia [52]. A comparative analysis of anxiety, fear and stress caused by witchcraft and its effects promoting MHD or dementia, was not in the scope of this review. However, studies on this concern would be of interest in SSA. It is generally very important that research be conducted by local researchers that have a deep understanding of the beliefs around witchcraft, since they are more likely to identify relevant factors that influence both the cause and the dealing with dementia.

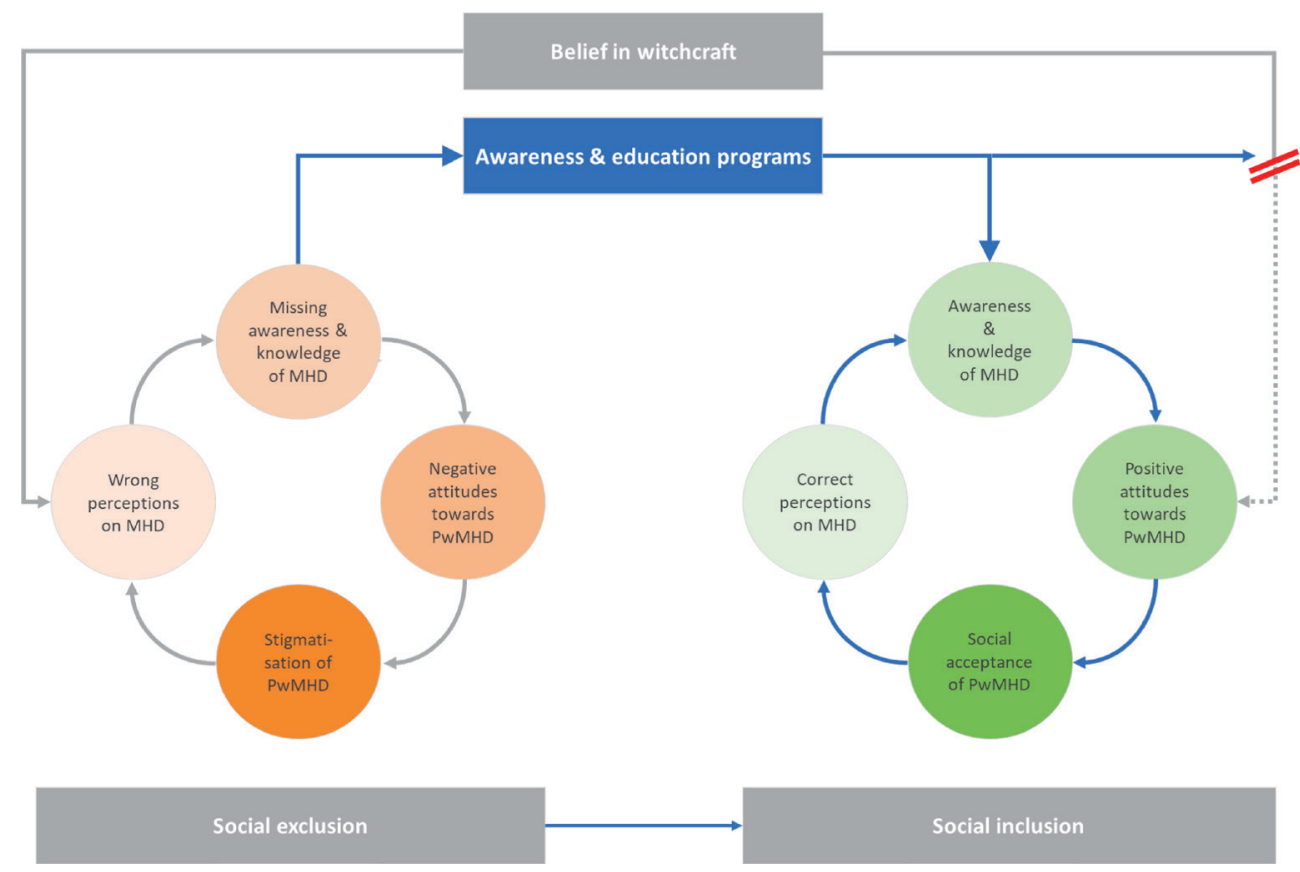

Figure 2. Summarisation of findings in circular flow of awareness challenges in Sub-Saharan Africa. MHD - mental health disorders, PwMHD - people living with mental health disorders.

Without raising awareness of those who wrongly stigmatised or accused PwMHD or PwD, misperceptions and concepts are likely to prevail. Helping PwMHD and PwD to live safely and in dignity, communities and neighbourhoods, health care workers, and politicians need to be educated about disease symptoms to understand the behaviour of people living with such diseases. Greater awareness and understanding people's behaviours could help change people's attitudes in a positive way, eg, lessening fear of PwMHD or PwD. Perceived dangerousness has been found as the main negative perception people held towards MHD, and these perceptions are most likely to promote discrimination [36]. Curbing social isolation and understanding 'strange' and 'abnormal' behaviour against the background of health care science might counter false accusation. Awareness and education could prevent prejudice that base people's behaviours 
on supernatural beliefs and instead enhance positive attitudes, as well as promote people's health status, social acceptance, and social inclusion. It is very important and mandatory for GCM and HCP to understand the aetiology of such conditions and it is fundamental to treat PwMHD or PwD with respect so that they can live in dignity, even if they show a violent and dangerous behaviour. Awareness through education will help to interrupt the circular flow of stigmatisation.

\section{Limitations}

Since there is generally a lack of studies addressing awareness challenges of dementia and related stigmatisation issues in SSA, this review also included studies facing the review's topic on MHD in general. Although there are similarities in the findings, the degree to which these results can be generalised is limited.

Moreover, the review focused on certain regions in SSA. There is a shortage of studies conducted especially in different Central and Southern African Countries. In this context, studies conducted among African communities located outside SSA have not been included. Furthermore, the review was limited to inclusion of English and German studies. Studies from francophone African countries and published in French might have given further insight into the topic. Even though some studies showed differences of stigmatising attitudes among rural and urban residents, or among different income situations and gender on those differences has not been focussed on [27,29,33,34,37].

\section{CONCLUSION}

It can be concluded that supernatural beliefs influence misperceptions of causes of dementia or other mental health disorders. Hence, such perceptions also influence people's concepts on diseases. The misperceptions are likely promoting negative and stigmatising attitudes towards people living with such conditions. Such beliefs are powerful and exist in all segments in Sub-Saharan African communities. Surprisingly, although people with a professional health education background like nurses and medical practitioners also often believe in causes such as witchcraft for diseases. Education campaigns on dementia disease and mental health disorders are mandatory to create greater awareness and knowledge on such conditions and its causes. Due to the results, which show that traditional beliefs influence the knowledge about diseases, they should play a role in the explanation of disease causes. Those influences should be also addressed in medical health curricula. In order to reduce stigmatisation and discrimination caused by the belief in witchcraft or other supernatural powers, researchers need to focus on a wide range of measures including awareness raising, so that the underlying causes for these practices are addressed as well. Furthermore, laws on witchcraft, like the Witchcraft Suppression Acts of 1957 of the Parliament of South Africa, to provide for the suppression of the practice of witchcraft and similar practices (eg, prohibition of various activities related to witchcraft or witch-hunting; South African Law Reform Commission, 2014), should be enacted or reviewed and reformed all over Sub-Saharan Africa. Even though there are legislations to prohibit witchcraft, those legislations need to be known and respected by societies to reduce the fear of witchcraft and all its consequences.

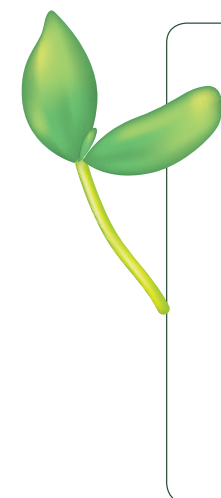

Acknowledgments: The authors would like to express our appreciation that Alzheimer's and Dementia Namibia and Alzheimer's and Related Disorders Association of Ghana are significantly contributing to improving awareness of dementia in their countries. We acknowledge support from the German Research Foundation (DFG) and the Open Access Publication Funds of Charité - Universitätsmedizin Berlin.

Funding: No funding supported this work.

Authorship contributions: Concept and design of review: SS, EK and AM; Literature search, screening: SS; data extraction and quality assessment: SS and AM; All authors were involved in writing the manuscript and approved the final version.

Competing interest: The authors completed the Unified Competing Interest form at www.icmje.org/coi_disclosure.pdf (available upon request from the corresponding author), and declare no conflicts of interest. 
1 World Health Organization. The global burden of disease: 2004 update. Geneva: WHO;2008.

2 World Health Organization. Mental Health Gap Action Programme (mhGAP). Geneva: WHO; 2008.

3 Jacob KS, Sharan P, Mirza I, Garrido-Cumbrera M, Seedat S, Mari JJ, et al. Mental health systems in countries: where are we now? Lancet. 2007;370:1061-77. Medline:17804052 doi:10.1016/S0140-6736(07)61241-0

4 World Health Organization. Mental Health Atlas. Geneva: WHO; 2005.

5 Watkins CC, Treisman GJ. Cognitive impairment in patients with AIDS - prevalence and severity. HIV AIDS (Auckl). 2015;7:35-47. Medline:25678819 doi:10.2147/HIV.S39665

6 Kapungwe A, Cooper S, Mwanza J, Mwape L, Sikwese A, Kakuma R, et al. Mental illness-stigma and discrimination in Zambia. Afr J Psychiatry (Johannesbo). 2010;13:192-203. Medline:20957318

7 Chibanda D, Cowan F, Gibson L, Weiss HA, Lund C. Prevalence and correlates of probable common mental disorders in a population with high prevalence of HIV in Zimbabwe. BMC Psychiatry. 2016;16:55. Medline:26926690 doi:10.1186/ s12888-016-0764-2

8 Kwobah E, Epstein S, Mwangi A, Litzelman D, Atwoli L. Prevalence of psychiatric morbidity in a community sample in Western Kenya. BMC Psychiatry. 2017;17:30. Medline:28100210 doi:10.1186/s12888-017-1202-9

9 Sevigny JJ, Albert SM, McDermott MP, McArthur JC, Sacktor N, Conant K, et al. Evaluation of HIV RNA and markers of immune activation as predictors of HIV-associated dementia. Neurology. 2004;63:2084-90. Medline:15596754 doi:10.1212/01.WNL.0000145763.68284.15

10 Ferri CP, Prince M, Brayne C, Brodaty H, Fratiglioni L, Ganguli M, et al. Global prevalence of dementia: a Delphi consensus study. Lancet. 2005;366:2112-7. Medline:16360788 doi:10.1016/S0140-6736(05)67889-0

11 ADI. Women and Dementia. A global research review. London: Alzheimer's Disease International (ADI). 2015.

12 George-Carey R, Adeloye D, Chan KY, Paul A, Kolcic I, Campbell H, et al. An estimate of the prevalence of dementia in Africa: A systematic analysis. J Glob Health. 2012;2:020401. Medline:23289076 doi:10.7189/jogh.02.020401

13 Spittel S, Wolf-Ostermann K. Challenges in health care for people with dementia in Ghana. Alzheimers Dement. 2013;9:488. doi:10.1016/j.jalz.2013.05.998

14 Spittel S, Kraus E, Maier A, Wolf-Ostermann K. Healthcare challenges of older people with and without dementia in Ghana: An expolratory pilot study. International Journal on Ageing in Developing Countries. 2018;3:116-31.

15 Corrigan PWK. Amy Kerr; Knudsen, Lissa. The stigma of mental illness: Explanatory models and methods for change. Appl Prev Psychol. 2005;11:179-90. doi:10.1016/j.appsy.2005.07.001

16 Alonso J, Buron A, Bruffaerts R, He Y, Posada-Villa J, Lepine JP, et al. Association of perceived stigma and mood and anxiety disorders: results from the World Mental Health Surveys. Acta Psychiatr Scand. 2008;1 18:305-14. Medline:18754833 doi:10.1111/j.1600-0447.2008.01241.x

17 Stefanovics EA, He H, Cavalcanti M, Neto H, Ofori-Atta A, Leddy M, et al. Witchcraft and Biopsychosocial Causes of Mental Illness: Attitudes and Beliefs About Mental Illness Among Health Professionals in Five Countries. J Nerv Ment Dis. 2016;204:169-74. Medline:26745309 doi:10.1097/NMD.0000000000000422

18 Fabrega H. Psychiatric Stigma in Non-Wester Societies. Compr Psychiatry. 1991;32:534-51. Medline:1778081 doi:10.1016/0010-440X(91)90033-9

19 Adewuya AO. Doctors' attitude towards people with mental illness in Western Nigeria. Soc Psychiatry Psychiatr Epidemiol. 2007;42:931-6. Medline:17721670 doi:10.1007/s00127-007-0246-4

20 Mavundla TR, Toth F, Mphelane ML. Caregiver experience in mental illness: a perspective from a rural community in South Africa. Int J Ment Health Nurs. 2009;18:357-67. Medline:19740145 doi:10.1111/j.1447-0349.2009.00624.x

21 Ndamba-Bandzouzi B, Nubukpo P, Mouanga A, Mbelesso P, Tognidé M, Tabo A, et al. Violence and witchcraft accusations against older people in Central and Western Africa: Toward a new status for the older individuals? Int J Geriatr Psychiatry. 2014;29:546-7. Medline:24706606 doi:10.1002/gps.4069

22 Moher D, Shamseer L, Clarke M, Ghersi D, Liberati A, Petticrew M, et al. PRISMA-P Group. Preferred reporting items for systematic review and meta-analysis protocols (PRISMA-P) 2015 statement. Syst Rev. 2015;4:1-9. Medline:25554246 doi:10.1186/2046-4053-4-1

23 Adebiyi AO, Fagbola MA, Olakehinde O, Ogunniyi A. Enacted and implied stigma for dementia in a community in south-west Nigeria. Psychogeriatrics. 2016;16:268-73. Medline:26551624 doi:10.1111/psyg. 12156

24 Adewuya AO, Makanjuola RO. Lay beliefs regarding causes of mental illness in Nigeria: pattern and correlates. Soc Psychiatry Psychiatr Epidemiol. 2008;43:336-41. Medline:18273532 doi:10.1007/s00127-007-0305-x

25 Adewuya AO, Makanjuola RO. Social distance towards people with mental illness in southwestern Nigeria. Aust N Z J Psychiatry. 2008;42:389-95. Medline:18473257 doi:10.1080/00048670801961115

26 Audu IA, Idris SH, Olisah VO, Sheikh TL. Stigmatization of people with mental illness among inhabitants of a rural community in northern Nigeria. Int J Soc Psychiatry. 2013;59:55-60. Medline:22131198 doi:10.1177/0020764011423180

27 Ayazi T, Lien L, Eide A, Shadar EJ, Hauff E. Community attitudes and social distance towards the mentally ill in South Sudan: a survey from a post-conflict setting with no mental health services. Soc Psychiatry Psychiatr Epidemiol. 2014;49:771-80. Medline:24136000 doi:10.1007/s00127-013-0775-y

28 Barke A, Nyarko S, Klecha D. The stigma of mental illness in Southern Ghana: attitudes of the urban population and patients' views. Soc Psychiatry Psychiatr Epidemiol. 2011;46:1191-202. Medline:20872212 doi:10.1007/s00127-0100290-3

29 Dogra N, Omigbodun O, Adedokun T, Bella T, Ronzoni P, Adesokan A. Nigerian secondary school children's knowledge of and attitudes to mental health and illness. Clin Child Psychol Psychiatry. 2012;17:336-53. Medline:21852317 doi:10.1177/1359104511410804 
30 Egbe CO, Brooke-Sumner C, Kathree T, Selohilwe O, Thornicroft G, Petersen I. Psychiatric stigma and discrimination in South Africa: perspectives from key stakeholders. BMC Psychiatry. 2014;14:191. Medline:24996420 doi:10.1186/1471244X-14-191

31 Faure-Delage AM. Alain Maxime; M’belesso, Pascal; Tabo,André; Bandzouzi, Bébène; Dubreuil, Catherine-Marie; Preux P-MC, Jean-Pierre; Nubukpo, Philippe. Socio-Cultural Perceptions and Representations of Dementia in Brazzaville, Republic of Congo: The EDAC Survey. Dement Geriatr Cogn Disord Extra. 2012;2:84-96. doi:10.1159/000335626

32 Girma E, Tesfaye M, Froeschl G, Moller-Leimkuhler AM, Muller N, Dehning S. Public stigma against people with mental illness in the Gilgel Gibe Field Research Center (GGFRC) in Southwest Ethiopia. PLoS One. 2013;8:e82116. Medline:24324756 doi:10.1371/journal.pone.0082116

33 Girma E, Moller-Leimkuhler AM, Muller N, Dehning S, Froeschl G, Tesfaye M. Public stigma against family members of people with mental illness: findings from the Gilgel Gibe Field Research Center (GGFRC), Southwest Ethiopia. BMC Int Health Hum Rights. 2014;14:2. Medline:24555444 doi:10.1186/1472-698X-14-2

34 Gureje O, Lasebikan VO, Ephraim-Oluwanuga O, Olley BO, Kola L. Community study of knowledge of and attitude to mental illness in Nigeria. Br J Psychiatry. 2005;186:436-41. Medline:15863750 doi:10.1192/bjp.186.5.436

35 Gureje O, Olley BO, Olusola EO, Kola L. Do beliefs about causation influence attitudes to mental illness? World Psychiatry. 2006;5:104-7. Medline:16946952

36 Igbinomwanhia NG, James BO, Omoaregba JO. The attitudes of clergy in Benin City, Nigeria towards persons with mental illness. Afr J Psychiatry (Johannesbo). 2013;16:196-200. Medline:23739822 doi:10.4314/ajpsy.v16i3.26

37 Kabir M, Iliyasu Z, Abubakar IS, Aliyu MH. Perception and beliefs about mental illness among adults in Karfi village, northern Nigeria. BMC Int Health Hum Rights. 2004;4:3. Medline:15320952 doi:10.1186/1472-698X-4-3

38 Mkhonto F, Hanssen I. When people with dementia are perceived as witches. Consequences for patients and nurse education in South Africa. J Clin Nurs. 2018;27:e169-76. Medline:28557051 doi:10.1111/jocn.13909

39 Mohamed-Kaloo Z, Laher S. Perceptions of mental illness among Muslim general practitioners in South Africa. S Afr Med J. 2014;104:350-2. Medline:25212202 doi:10.7196/SAMJ.7863

40 Mushi D, Rongai A, Paddick SM, Dotchin C, Mtuya C, Walker R. Social representation and practices related to dementia in Hai District of Tanzania. BMC Public Health. 2014;14:260. Medline:24642112 doi:10.1186/1471-2458-14-260

41 Ofori-Atta A, Cooper S, Akpalu B, Osei A, Doku V, Lund C, et al. Common understandings of women's mental illness in Ghana: results from a qualitative study. Int Rev Psychiatry. 2010;22:589-98. Medline:21226647 doi:10.3109/09540 261.2010 .536150

42 Patel V, Butau M. Fuyane. Concepts of mental illness and medical pluralism in Harare. Psychol Med. 1995;25:485-93. Medline:7480429 doi:10.1017/S0033291700033407

43 Quinn N, Knifton L. Beliefs, stigma and discrimination associated with mental health problems in Uganda: implications for theory and practice. Int J Soc Psychiatry. 2014;60:554-61. Medline:24097841 doi:10.1177/0020764013504559

44 Ssebunnya J, Kigozi F, Ndyanabangi S, Cooper S. Stakeholders' perceptions of the main challenges facing Uganda's mental health care system: A qualitative analysis. Int J Cult Ment Health. 2011;4:54-67. doi:10.1080/17542863.2010.503047

45 Gureje O, Lasebikan VO. Use of mental health services in a developing country. Results from the Nigerian survey of mental health and well-being. Soc Psychiatry Psychiatr Epidemiol. 2006;41:44-9. Medline:16341828 doi:10.1007/ s00127-005-0001-7

46 Ronzoni P, Dogra N, Omigbodun O, Bella T, Atitola O. Stigmatization of mental illness among Nigerian schoolchildren. Int J Soc Psychiatry. 2010;56:507-14. Medline:19651693 doi:10.1177/0020764009341230

47 Mkhonto F, Hanssen FMI. When people with dementia are perceived as witches. Consequences for patients and nurse education in South Africa. J Clin Nurs. 2018;27:e169-76. Medline:28557051 doi:10.1111/jocn.13909

48 Strümpher J, van Rooyen RM, Topper K, Andersson LMC, Schierenback I. Barriers to accessing mental health care in the Eastern Cape Province of South Africa. Afr J Nurs Midwifery. 2014;16:45-59. doi:10.25159/2520-5293/1487

49 Bigelow J, Berrett S, Kimuli I, Katabira E. Perceptions of epilepsy among first-year medical students at Mulago Hospital in Kampala, Uganda. Epilepsy Behav. 2015;51:28-32. Medline:26253598 doi:10.1016/j.yebeh.2015.06.020

50 Prince M, Acosta D, Albanese E, Arizaga R, Ferri CP, Guerra M, et al. Ageing and dementia in low and middle income countries - Using research to engage with public and policy makers. Int Rev Psychiatry. 2008;20:332-43. Medline:18925482 doi:10.1080/09540260802094712

51 Bain LE, Awah PK, Takougang I, Sigal Y, Ajime TT. Public awareness, knowledge and practice relating to epilepsy amongst adult residents in rural Cameroon-case study of the Fundong health district. Pan Afr Med J. 2013;14:32. Medline:23503525 doi:10.11604/pamj.2013.14.32.2284

52 Mah L, Szabuniewiczb C, Fioccoc AJ. Can anxiety damage the brain? Curr Opin Psychiatry. 2016;29:56-63. Medline:26651008 doi:10.1097/YCO.0000000000000223 